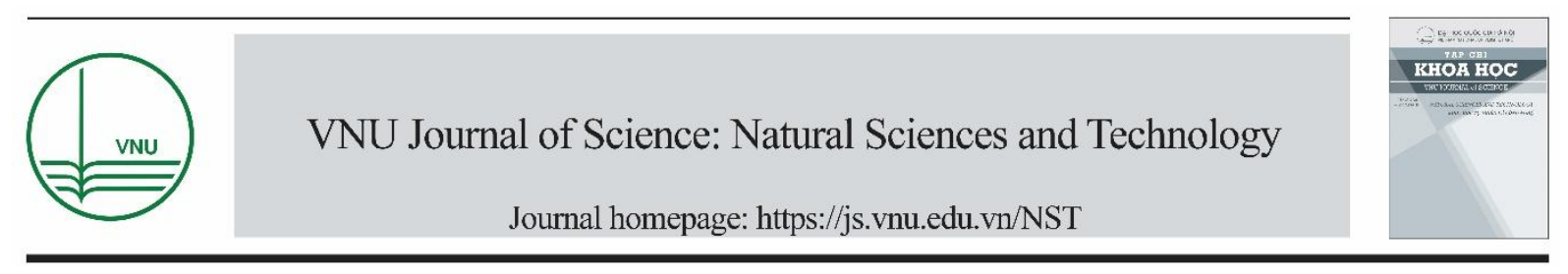

Original Article

\title{
Culture Condition for High Biomass Production of Probiotic Yeast Saccharomyces Boulardii SB2 in Shake Flask and 30 Littre Scale
}

\author{
Dao Thi Luong*, Ha Thi Hang, Duong Van Hop \\ VNU Institute of Microbiology and Biotechnology, 144 Xuan Thuy, Hanoi, Vietnam \\ Received 25 March 2019 \\ Revised 09 April 2019; Accepted 21 July 2019
}

\begin{abstract}
Probiotic properties in vitroof the Saccharomyces boulardii SB2 yeast, was isolated from fruit at Cuc Phuong National Park were evaluated based on biological characteristics and tolerance in simulated intestinal conditions. In the present work, studies were carried out to improve cell growth kinetics to produce cell mass of this biotherapeutic yeast in shake flaskand 30-L bioreactor levels. In case of shake flask, the highest biomass was obtained under the culture conditions as YM medium, at $37^{\circ} \mathrm{C}, \mathrm{pH} 6$, inoculum concentration of $5 \%$, with shaking for $32 \mathrm{~h}$; the best sources of carbon and nitrogen were found to be glucose and mixture of peptone, yeast extract, malt extract; cell dry weight and cell density reached $2.43 \mathrm{~g} \mathrm{~L}^{-1}$ and $10^{9} \mathrm{CFU} / \mathrm{ml}$ repetitively. During 30-L bioreactor cultivation, the maximal cell mass in agitation speed of $200 \mathrm{rpm}$, aeration rate of $1.2 \mathrm{v} \mathrm{v}^{-}$ ${ }^{1} \mathrm{~min}^{-1}$; at $32 \mathrm{~h}$ of incubation, was $3.58 \mathrm{~g} \mathrm{~L}^{-1}$ in $\mathrm{pH}$ controlled culture and $3.08 \mathrm{~g} \mathrm{~L}^{-1}$ in uncontrolled $\mathrm{pH}$. This is considered as the first step for cell mass production of this probiotic yeast in industrial scale.
\end{abstract}

Keywords: Saccharomyces boulardii SB2, probiotic, biomass, shake flask, 30-L bioreactor.

\footnotetext{
* Corresponding author.

Email address: luongdt@vnu.edu.vn

https://doi.org/10.25073/2588-1140/vnunst.4879
} 


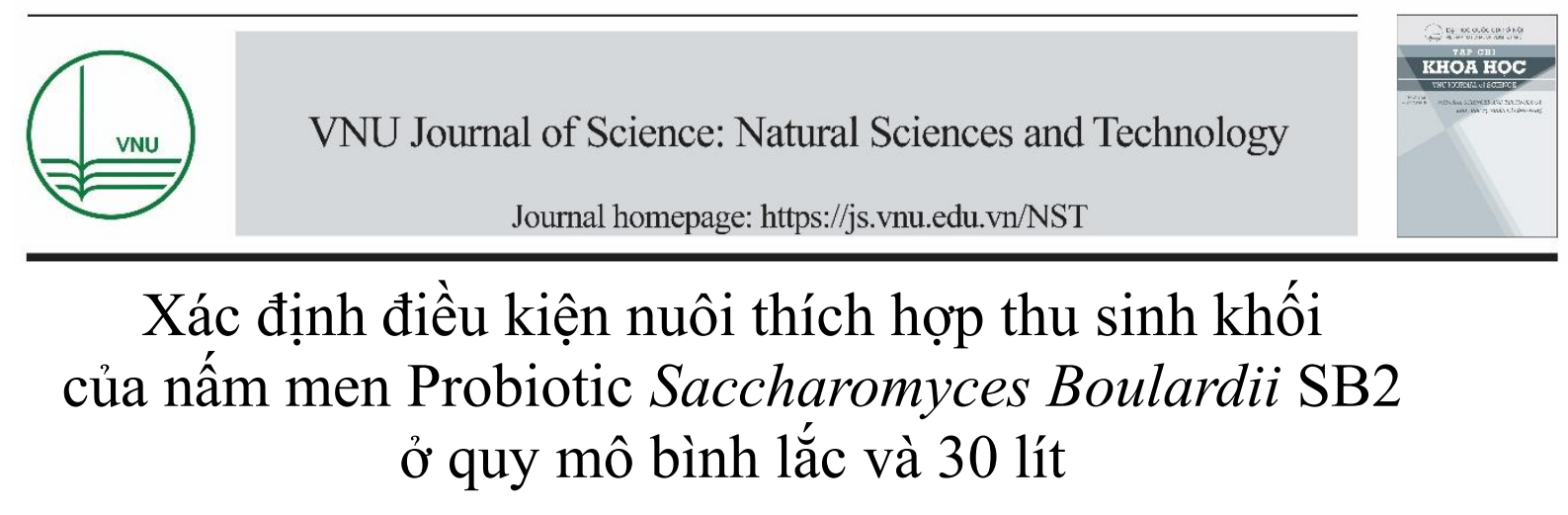

\author{
Đào Thị Lương*, Hà Thị Hằng, Dương Văn Hợp \\ Viện Vi sinh vật và Công nghệ Sinh học, ĐHQGHN, 144 Xuân Thủy, Hà Nội, Việt Nam \\ Nhận ngày 25 tháng 3 năm 2019 \\ Chỉnh sửa ngày 09 tháng 4 năm 2019; Chấp nhận đăng ngày 21 tháng 7 năm 2019
}

\begin{abstract}
Tóm tắt: Đặc tính probiotic trong điều kiện in vitro của chủng nấm men Saccharomyces boulardii SB2 được phân lập từ quả rụng ở Vườn Quốc gia Cúc Phương, đã được đánh giá dựa vào các đặc điểm sinh học và khả năng chống chịu trong môi trường ruột mô phỏng. Trong nghiên cứu này, chủng nấm men được nghiên cứu về động học sinh trưởng cho sản xuất sinh khối cao ở quy mô bình lắc và trong thiết bị lên men 30 lít. Nuôi trên bình lắc, sinh khối cao nhất thu được trên môi trường $\mathrm{YM}$, nhiệt độ $37^{\circ} \mathrm{C}, \mathrm{pH} 6$, chế độ lắc, tỉ lệ giống cấy $5 \%$, nguồn cacbon là glucose, nguồn nitơ là hỗn hợp của pepton, cao men, cao malt; thời gian nuôi 32 giờ, sinh khối và số lượng tế bào đạt 2,43 $\mathrm{g} / \mathrm{l}$ và $10^{9} \mathrm{CFU} / \mathrm{ml}$. Nuôi trong thiết bị lên men 30 lít, sinh khối đạt cao nhất ở tốc độ khuấy 200 $\mathrm{v} / \mathrm{ph}$; tốc độ sục khí 1,2 lít khí/lít dịch/phút; thời gian lên men 32 giờ, đạt $3,58 \mathrm{~g} / \mathrm{l}$ dưới điều kiện $\mathrm{pH}$ được kiểm soát và $3,08 \mathrm{~g} / \mathrm{l}$ khi $\mathrm{pH}$ không kiểm soát. Đây được coi là bước khởi đầu để sản xuất ở quy mô công nghiệp cho nấm men probiotic này.
\end{abstract}

Tù khóa: Saccharomyces boulardii SB2, probiotic, sinh khối, bình lắc, thiết bị lên men 30 lít.

\section{Giới thiệu}

Probiotic là vi sinh vật sống được bổ sung vào thức ăn, mang lại lợi ích cho vật chủ bằng cách cải thiện và cân bằng hệ vi sinh đường ruột [1]. Saccharomyces boulardii, một loại nấm men không gây bệnh phát triển tối ưu ở nhiệt độ cơ thể, đã được thử nghiệm về hiệu quả của nó trong phòng chống tiêu chảy liên quan đến kháng khuẩn. Bên cạnh các tính chất probiotic, $S$. boulardii cũng được sử dụng như tác nhân trị liệu sinh học và được sử dụng cho trị liệu đặc hiệu chống lại nhiều bệnh [2]. Cơ chế hoạt động của loại nấm men này dựa trên hoạt động ức chế tác nhân gây bệnh trong ruột, ức chế hoạt động của độc tố vi sinh vật [3], kích thích globulin miễn dịch $\mathrm{A}[4]$ và tác dụng đến niêm mạc ruột [5]. Do đó, việc sản xuất sinh khối của nấm men này như là sản phẩm probiotic/sinh học trị liệu có giá trị cao là chủ đề hấp dẫn cho nhiều nhóm

\footnotetext{
* Tác giả liên hệ.

Địa chỉemail: luongdt@vnu.edu.vn

https://doi.org/10.25073/2588-1140/vnunst.4879
} 
nghiên cứu. Giống như men bánh mì, $S$. boulardii sử dụng nguồn carbon cho sản xuất sinh khối dựa trên thành phần môi trường và điều kiện nuôi cấy. Hơn nữa, một số nghiên cứu đã được tiến hành để tối ưu hóa việc sản xuất sinh khối Saccharomyces cerevisiae bằng các loại môi trường khác nhau trong bình lắc và sử dụng các thông số nuôi khác nhau trong thiết bị lên men. Các quy trình nuôi khác nhau trong các thiết bị lên men theo mẻ, hay lên men liên tục cũng đang được nghiên cứu nhằm tối ưu hóa quá trình tạo sinh khối cao của $S$. cerevisiae, $S$. boulardii và những vi khuẩn probiotic khác [6].

Nghiên cứu được thực hiện nhằm mục tiêu phát triển mô hình bán công nghiệp để sản xuất sinh khối Saccharomyces boulardii cao cho các ứng dụng trị liệu sinh học và probiotic sử dụng các môi trường và thông số khác nhau ở cả hai điều kiện nuôi bình lắc và thiết bị lên men.Trong bình lắc, nuôi cấy $S$. Boulardii được thử nghiệm trên 8 môi trường, tiếp theo là lựa chọn các chế độ nuôi khác nhau. Cuối cùng, nghiên cứu về ảnh hưởng của các thông số lên men đến việc sản xuất sinh khối của $S$. boulardii trong thiết bị lên men 30 lít làm khởi đầu cho sản xuất ở quy mô công nghiệp.

\section{Nguyên liệu và phương pháp}

Vi sinh vật

- Chủng nấm men Saccharomyces cerevisiae var. boulardii SB2 được lưu giữ tại Bảo tàng Giống chuẩn Việt Nam (VTCC), Viện Vi sinh vật và Công nghệ sinh học, ĐHQGHN.

- Vi sinh vật kiểm định: Staphylococcus aureus VTCC-B-0658.

\section{Môi trường}

- Môi truòng YM agar (g/l): Glucose-10; Pepton-5; Cao men-3; Cao malt-3; Agar-16; Nước cất-1 lít; pH6,0 $\pm 0,2$

- Môi truò̀ng dịch thể nuôi Saccharomyces (g/l): (1)Hansen: Glucose-30; Pepton-10; $\mathrm{KH}_{2} \mathrm{PO}_{4}-3 ; \quad \mathrm{MgSO}_{4} .7 \mathrm{H}_{2} \mathrm{O} \quad-2$; cao men-1. (2)Malt extract (ME): Cao malt-20; Glucose20; Pepton-1. (3)Sabouraud's (Sab): Glucose-
20; Pepton-10; $\mathrm{KH}_{2} \mathrm{PO}_{4}-1,5 ; \mathrm{MgSO}_{4} .7 \mathrm{H}_{2} \mathrm{O}-1,0$; $\mathrm{NaNO}_{3}-1$,0. (4)PDB: Khoai tây-200; Glucose20. (5)YEGP: Glucose-20; Cao men-5; Pepton10. (6) YM: Glucose-10; Pepton-5; Cao men-3; Cao malt-3. (7) YM bổ sung khoáng (YM-K): Glucose-10; Pepton-5; Cao men-3; Cao malt-3; $\mathrm{KH}_{2} \mathrm{PO}_{4}-3$; $\mathrm{MgSO}_{4} .7 \mathrm{H}_{2} \mathrm{O}-2$. (8)YPD: Pepton20; Cao men-10; Glucose-20.

\section{Phuoong pháp}

\section{- Xác định khả năng sinh truởng}

Xác định sinh khối: Chủng nấm men được nuôi trong bình $250 \mathrm{ml}$ chứa $50 \mathrm{ml}$ dịch lên men hoặc trong thiết bị lên men 301 chứa 201 môi trường được lấy mẫu tại các khoảng thời gian khác nhau. Sinh khối khô được tính dựa trên đường chuẩn $\mathrm{OD}_{600}$ đã chuẩn bị theo phương pháp mô tả của Chin và cộng sự, (2015) [6].

Xác định số lương tế bào: bằng phương pháp pha loãng theo mô tả của Diep và cộng sự (2014) [7].

- Hoạt tính kháng khuẩn: Dịch ly tâm phía trên của tế bào được sử dụng để xác định hoạt tính kháng Staphylococcus aureus VTCCB-0658 bằng phương pháp khuếch tán trên đĩa thạch.

- Phương pháp xác định hàm lượng glucose

Sử dụng thuốc thử DNS theo phương pháp của Miller, 1959 [8].

- pH môi truò̀ng được kiểm tra trên thiết bị đo $\mathrm{pH}$ theo hướng dẫn của nhà sản xuất.

- Nghiên cứu điều kiện nuôi nấm men Saccharomyces.

Lựa chọn điều kiện nuôi thich hợp trong bình lắc

Nấm men được nuôi lắc trong bình tam giác trên 8 môi trường (Hansen, Malt extract, Sabouraud's, YEGP, YM, YPD, YM bổ sung khoáng và $\mathrm{PDB})$. Thử nghiệm sinh trưởng ở các nhiệt độ khác nhau $(20,25,30,35,40,45$ và $\left.50^{\circ} \mathrm{C}\right) ; \mathrm{pH}$ thay đổi từ 3 đến 9 ; Tỉ lệ giống cấy từ 0,2 đến $10 \%$; Các nguồn cacbon thay thế là fructose, galactose,glucose, lactose, maltose, mannitol, saccharose, tinhbột; Nguồn nitơ thay thế là cao malt, cao men, casein, pepton, $\mathrm{NaNO}_{3}$, $\mathrm{NaNO}_{2},\left(\mathrm{NH}_{4}\right)_{2} \mathrm{SO}_{4}$ và urê; nuôi ở chế độ cấp khí 
lắc, tĩnh và vi khí. Thời gian nuôi liên tục từ 0 đến 60 giờ đã được thử nghiệm cho khả năng tạo sinh khối, $\mathrm{pH}$ sau nuôi và hàm lượng glucose.

Lựa chọn điều kiện nuôi thích hợp trên thiết bị lên men 30 lít

Nấm men được nuôi trong thiết bị lên men 30 1, cấy $5 \%$ giống; nhiệt độ nuôi ở $37^{\circ} \mathrm{C} ; \mathrm{pH}$ ban đầu được điều chỉnh đến 6,0 sau khi khử trùng. pH kiểm soát ở cùng một giá trị trong quá trình nuôi được điều chỉnh bằng $2,5 \mathrm{M} \mathrm{NaOH}$ và $2,5 \mathrm{M} \mathrm{HCl}$. Chất chống tạo bọt vô trùng đã được sử dụng trong quá trình nuôi. Sinh khối khô được xác định ở các tốc độ khuấy 50,100, 150, 200 và $250 \mathrm{v} / \mathrm{ph}$; lượng khí cung cấp được thay đổi $(0,8$; 1,$0 ; 1,2 ; 1,4$ và 1,61 khí/lít dịch/phút). Xác định $\mathrm{pH}$ sau nuôi; hàm lượng glucose và sinh khối khô theo thời gian nuôi $8,16,24,32,40,48$, và 60 giờ dưới điều kiện $\mathrm{pH}$ được kiểm soát và không kiểm soát.

Các thí nghiệm được tiến hành ba lần, kết quả là trung bình của ba thử nghiệm độc lập.

\section{Kết quả và thảo luận}

Đặc tính probiotic trong điều kiện in vitro của chủng nấm men $\mathrm{SB} 2$, phân lập từ quả rụng ở Vườn Quốc gia Cúc Phương, đã được đánh giá dựa vào các đặc điểm sinh học và khả năng chống chịu trong điều kiện ruột mô phỏng. Chủng nấm men được định danh là $S$. cerevisiae var. boulardii SB2 và mang đầy đủ các đặc tính probiotic như: sinh trưởng ở $37^{\circ} \mathrm{C}$, có khả năng sinh các hoạt chất kháng một số vi khuẩn gây bệnh, chịu muối mật $(0,3 \%)$, tồn tại trong điều kiện khắc nghiệt của dạ dày và ruột, có khả năng bám dính vào các tế bào biểu mô ruột,và không bị ảnh hưởng bởi các kháng sinh kháng khuẩn thông dụng. Trong nghiên cứu này, chủng SB2 được nghiên cứu các điều kiện nuôi thích hợp cho sản xuất sinh khối cao ở quy mô bình lắc và thiết bị lên men 301.

\section{Lựa chọn điều kiện nuôi thích hợp trong bình lắc}

Nuôi trong bình lắc chủng Saccharomyces boulardii SB2 bao gồm các thực nghiệm: lựa chọn môi trường, nhiệt độ, giá trị $\mathrm{pH}$, tỷ lệ giống, chế độ cấp khí, nguồn cacbon, nguồn nitơ và thời gian nuôi được đánh giá riêng biệt.

Tám loại môi trường thông thường sử dụng nuôi nấm men đã được lựa chọn để nghiên cứu khả năng tạo sinh khối và khả năng kháng các vi sinh vật đường ruột của $S$. boulardii SB2 (Hình 1). Quá trình tạo sinh khối tế bào phụ thuộc rất nhiều điều kiện trong đó có thành phần môi trường, do đó, việc nghiên cứu, lựa chọn môi trường thích hợp có vai trò vô cùng quan trọng. Trong tám loại môi trường nuôi chủng SB2, sinh khối cao hơn trên các môi trường có chứa cao men (Bao gồm: Hansen, YEGP, YM, YMKhoáng và YPD). Sinh khối tế bào đạt cao nhất (đạt 2,35 g/l) trên môi trường YM (bao gồm cao men, cao malt, pepton và glucose) là môi trường có tỷ lệ các thành phần dinh dưỡng thích hợp cho sự sinh trưởng và phát triển của chủng $\mathrm{SB} 2$. Tiếp theo là các môi trường Hansen, YM-Khoáng, YPD và YEGP đạt 2,08-2,24 g/l khi nuôi ở $37^{\circ} \mathrm{C}$ trong 48 giờ. Ở các môi trường còn lại không có cao men, sinh khối thấp hơn từ 1,75 - 1,92 g/l. Cao men được sử dụng rộng rãi trong các công thức môi trường là nguồn giàu các axit amin, vitamin và các yếu tố tăng trưởng. Nó đóng một vai trò quan trọng đối với sự phát triển tế bào và do đó, bổ sung cao men là cần thiết để hỗ trợ sự phát triển của tế bào và đạt được mật độ tế bào cao [9]. Chin và cộng sự (2015) nuôi chủng Saccharomyces boulardii ATCC-MYA-796 trên 5 môi trường ở $37^{\circ} \mathrm{C}$ trong 24 giờ lắc, sinh khối tế bào đạt cao nhất $(2,57 \mathrm{~g} / \mathrm{l})$ thu được ở môi trường 2 (bao gồm glucose, corn steep liquor, NaNO3, và các loại khoáng). Bốn môi trường còn lại, sinh khối đạt $0,7-2,0$ g/l [6]. Nuôi bình lắc trên 3 môi trường YMG, CSM và $\mathrm{CSM}$ bổ sung cao men trong nghiên cứu của El-Enshasy và cộng sự (2008) cho các kết quả khác nhau, sinh khối cao nhất thu được ở môi trường CSM bổ sung cao men $(3,1 \mathrm{~g} / \mathrm{l})$ sau 12 giờ nuôi, tiếp theo là môi trường $\mathrm{YMG}(2,5 \mathrm{~g} / \mathrm{l})$ sau 22 giờ nuôi và thấp nhất khi nuôi trên môi trường CSM, đạt $1,5 \mathrm{~g} / \mathrm{l}$ sau 12 giờ nuôi. 


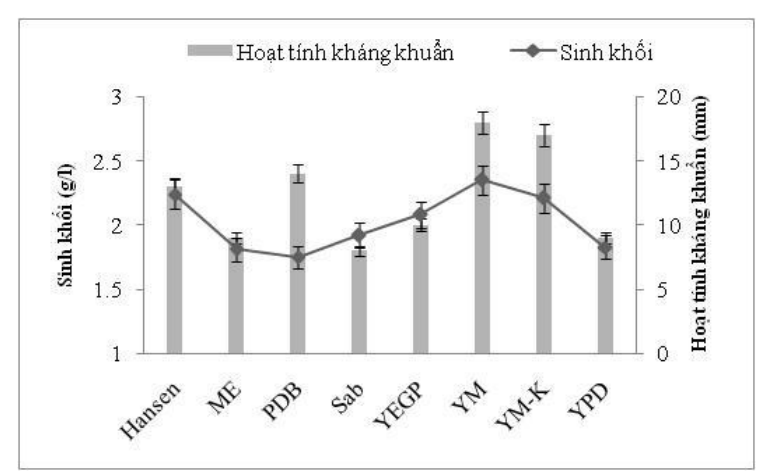

Hình 1. Lựa chọn môi trường nuôi thích hợp.

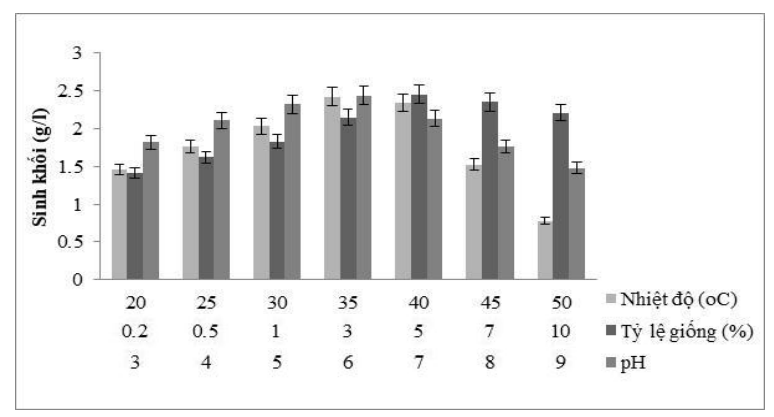

Hình 2. Lựa chọn nhiệt độ, pH nuôi và tỷ lệ giống cấy thích hợp.

Khả năng kháng Staphylococcus aureus của chủng SB2 cũng khác nhau trên các môi trường. Đường kính vòng kháng lớn nhất trên môi trường $\mathrm{YM}$ và $\mathrm{YM}-K$ hoáng $(17-18 \mathrm{~mm})$, tiếp theo là môi trường $\mathrm{PDB}$ và Hansen $(13-14 \mathrm{~mm})$, kém hơn ở 4 môi trường còn lại, vòng kháng từ 8 - 10 mm (Hình 1). Các hoạt tính probiotic của S. cerevisiae var. boulardii chống lại tác nhân gây bệnh của con người có liên quan đến giảm số lượng tế bào và khả năng hoạt động của vi khuẩn và khả năng gắn kết với bề mặt tế bào của nấm men. Nghiên cứu của Rajkowska và cộng sự (2012) xác định ảnh hưởng của bảy loại nấm men probiotic S.cerevisiae var.boulardii trên các vi khuẩn gây bệnh của con người: Escherichia coli, Enterococcus faecalis, Listeria monocytogenes, Pseudomonas aeruginosa, Salmonella typhimurium và Staphylococcus aureus. Kết quả cho thấy số lượng tế bào vi khuẩn giảm đáng kể đã được quan sát thấy khi nuôi hỗn hợp với nấm men probiotic. Phần lớn các chủng vi khuẩn đều bị rút ngắn thời gian pha lag khoảng $0,3-6,15$ giờ. Các vi khuẩn đạt tốc độ tăng trưởng tối đa trong thời gian ngắn hơn $0,23-3,98$ giờ so với trường hợp nuôi đơn chủng. Hoạt tính probiotic của $S$. cerevisiae var. boulardii chống lại vi sinh vật gây bệnh bằng cách sản xuất các hợp chất ức chế [10]. Một số khác giải thích tác dụng bảo vệ của nấm men chống lại vi khuẩn gây bệnh như điều hòa miễn dịch, sản sinh độc tố và cạnh tranh vị trí bám dính hoặc cạnh tranh chất dinh dưỡng [11].

Sinh trưởng và phát triển của chủng SB2 phụ thuộc rõ rệt vào nhiệt độ (Hình 2). Sinh trưởng tốt nhất trong khoảng nhiệt độ $35-40^{\circ} \mathrm{C}$, sinh khối khô đạt 2,34 - 2,42 g/l, sau 48 giờ nuôi. Các nghiên cứu trước đây đã chứng minh rằng Saccharomyces boulardii sinh trưởng tốt ở nhiệt độ $37^{\circ} \mathrm{C}$ so với các chủng khác thuộc chi Saccharomyces sinh trưởng ở nhiệu độ thấp hơn $[12,13]$. Đây là các khoảng nhiệt độ gần với nhiệt độ cơ thể người và động vật nên rất có lợi khi sử dụng chế phẩm probiotic.

Chủng SB2 có khả năng sinh trưởng ở các pH nghiên cứu từ 3 - 9; Sinh khối tăng từ $\mathrm{pH} 3$ 6 và giảm từ $\mathrm{pH} 7$ - 9; đạt giá trị cao nhất ở $\mathrm{pH} 6$. Đây là chủng có khả năng chịu $\mathrm{pH}$ thấp tốt, sinh khối đạt $75 \%$ ở pH3 so với sinh khối cao nhất ở pH6 (Hình 2). Trong nghiên cứu của Rajkowska và cộng sự, (2010), các chủng $S$. boulardii trong các sản phẩm thuốc sinh trưởng tốt ở $37^{\circ} \mathrm{C}$, có khả năng chịu pH thấp hơn, tồn tại trong dịch dạ dầy và chịu muối mật tốt hơn các nấm men phân lập từ kefir [14]. Khi sốc nhiệt ở $52{ }^{\circ} \mathrm{C}, S$. boulardii đã được chứng minh là có khả năng chống chịu tốt hơn (tồn tại $65 \%$ ) so với $S$. cerevisiae W303 (45\%) [15]. Khả năng chịu pH thấp của $S$. boulardii có thể do nhiều yểu tố khác nhau như kích thước tế bào, thành phần của vách tế bào vV...[12].

Tỷ lệ giống cấy là một trong những thông số quan trọng trong nghiên cứu điều kiện lên men. Trong thí nghiệm này, tỉ lệ giống $0,2-10 \%$ được kiểm tra, sinh khối thấp nhất khi cấy $0,2 \%$ giống; sinh khối tăng dần khi cấy lượng giống tăng đền $5 \%$ và có xu hướng giảm nhẹ khi cấy giống trên 7\% (Hình 2). Sinh khối đạt giá trị cao nhất khi cấy $5 \%$ giống. 
Khi thay đổi nguồn cacbon là glucose bằng các nguồn đường fructose, galactose, lactose, maltose, mannitol, tinh bột, và saccharose, chủng SB2 sinh trưởng tốt trên nguồn cacbon là fructose, maltose, mannitol và saccharose (đạt $2,21-2,36 \mathrm{~g} / \mathrm{l})$. Tuy nhiên sinh khối đạt cao nhất ở nguồn cacbon là glucose $(\mathrm{D} / \mathrm{C}+)$ là $2,46 \mathrm{~g} / 1$. Ở các nguồn cacbon còn lại: galactose, lactose, tinh bột, sinh khối đạt 1,51 - 1,84 g/l (Hình 3).

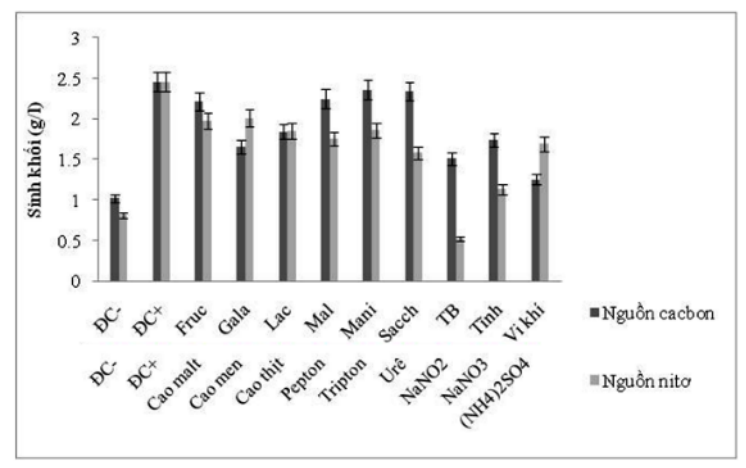

Hình 3. Lựa chọn nguồn cacbon, nitơ và chế độ khí thích hợp.

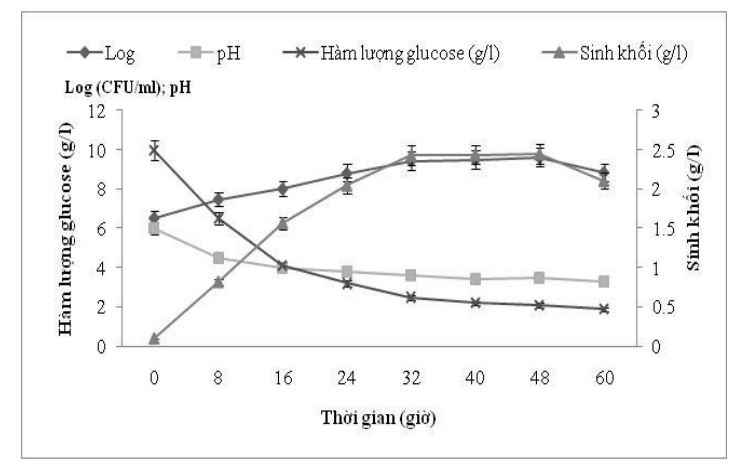

Hình 4. Lựa chọn thời gian nuôi thích hợp ở quy mô bình lắc.

Nuôi chủng SB2 trên môi trường YM, thay lần lượt các nguồn nitơ hữu cơ là cao malt, cao men, cao thịt, pepton, tripton, urê; và các nguồn vô co: $\mathrm{NaNO}_{2}, \mathrm{NaNO}_{3}, \mathrm{NH}_{4}\left(\mathrm{SO}_{4}\right)_{2}$. Nguồn nitơ ảnh hưởng nhiều đến sinh trưởng của chủng $\mathrm{SB} 2$, sinh khối cao hơn khi thay bằng các nguồn hữu cơ đơn từ 1,58 - 2,01 g/l. Các nguồn nitơ vô cơ đều cho kết quả thấp hơn đáng kể so với nguồn nitơ hữu cơ, chỉ đạt 0,52 - 1,69 g/l; $\mathrm{NaNO}_{2}$ còn gây ức chế sự sinh trưởng. Trong khi đó, nguồn nitơ hỗn hợp của pepton, cao malt, cao men $(\mathrm{DC}+)$ cho sinh khối cao nhất, đạt 2,46 g/l (Hình 3).

Nuôi chủng SB2 trong môi trường YM, ở 37 ${ }^{\circ} \mathrm{C}$, với $5 \%$ giống, 48 giờ với các chế độ khí khác nhau: lắc, tĩnh và vi khí. Kết quả hình 3 , cho thấy đây là chủng hiếu khí, ở chế độ lắc tạo sinh khối cao nhất và sinh khối thấp dần ở chế độ tĩnh và vi khí.

Nghiên cứu động học phát triển của tế bào, $\mathrm{pH}$ thay đổi và lượng glucose tiêu thụ trong quá trình nuôi của $S$. boulardii SB2 được tiến hành ở điều kiện bình lắc trong thời gian 60 giờ liên tục. Tế bào phát triển theo cấp số nhân mà không có giai đoạn lag đáng kể và đạt được sinh khối 2,43 $\mathrm{g} / \mathrm{l}$ và số lượng tế bào cao nhất sau 32 giờ nuôi (hình 4). Sinh khối và số lượng tế bào duy trì đến 48 giờ nuôi và giảm nhẹ sau đó, đạt $2,11 \mathrm{~g} / \mathrm{l}$ vào cuối thời gian nuôi. Điều này cho thấy, sinh trưởng đạt đến pha ổn định sau 32 giờ có thể là kết quả của sự tích tụ các sản phẩm phụ hoặc giới hạn chất dinh dưỡng. Trong quá trình tăng trưởng tế bào, $\mathrm{pH}$ môi trường giảm dần và đạt giá trị 3,6 sau 32 giờ nuôi. Sau thời gian đó, $\mathrm{pH}$ vẫn giữ nguyên trong khoảng 3,3 - 3,5 cho đến khi kết thúc quá trình nuôi. Tốc độ tiêu thụ glucose cao hơn trong 16 giờ nuôi ban đầu. Vào cuối thời gian nuôi, $20 \%$ lượng glucose đã không được sử dụng bởi tế bào bước vào pha ổn định và hạn chế sử dụng nguồn cacbon (Hình 4). Trong nghiên cứu của El-Enshasy và cộng sự (2008), nuôi chủng Saccharomyces boulardii ATCC-MYA-796 trên môi trường CSM (bổ sung cao nấm men $5 \mathrm{~g} / \mathrm{l}$ ) trong bình lắc, tế bào tăng trưởng theo cấp số nhân, đạt trọng lượng khô cao nhất $3,1 \mathrm{~g} / \mathrm{l}$ sau 12 giờ nuôi và giảm dần sau đó; độ $\mathrm{pH}$ của môi trường giảm dần, đạt giá trị thấp nhất là 2,9 sau 17 giờ. Hàm lượng glucose còn lại $25 \%$ vào cuối thời gian nuôi [9].

Lự chọn điều kiện nuôi thích hơp trên thiết bị lên men 30 lít

Tốc độ khuấy có vai trò lớn đến sinh trưởng của nấm men trong các thiết bị lên men, nó vừa có tác dụng đảo trộn môi trường và còn giúp phân tán đều dinh dưỡng tiếp xúc với bề mặt của nấm men, làm tăng khả năng hấp thụ dinh dưỡng 
của tế bào. Chủng nghiên cứu được nuôi trên thiết bị 30 lít chứa 20 lít môi trường $\mathrm{YM}$, ơ $^{3} 37^{\circ} \mathrm{C}$, với $5 \%$ giống, thời gian 32 giờ. $\mathrm{SB} 2$ là chủng hiếu khí do vậy mật độ tế bào thay đổi khi thay đổi tốc độ khuấy trộn. Sinh khối tăng khi tăng tốc độ khuấy từ 50 - 200 vòng/phút và có xu thế giảm nhẹ khi tăng cao hơn. Tốc độ khuấy thích hợp cho sự sinh trưởng của chủng SB2 là 200 vòng/phút với sinh khối đạt 2,94g/l (Hình 5).

Sục khí nhằm cung cấp oxi cho quá trình sinh trưởng của nấm men. Trong thí nghiệm này, sinh khối chủng SB2 tăng khi tăng tốc độ sục khí và đạt giá trị cao nhất ở 1,2 lít khí/lít dịch/phút đạt 3,05 g/l. Sinh trưởng không tăng khi tốc độ sục khí cao hơn (Hình 5). Khi tăng tốc độ sục khí từ 1,0 lít khí/lít dịch/phút lên 1,5 lít khí/lít dịch/phút, sinh khối của chủng Saccharomyces cerevisiae var. boulardiiSB-17 tăng 30\%; pH môi trường và tốc độ tiêu thụ glucose giảm mạnh [16].

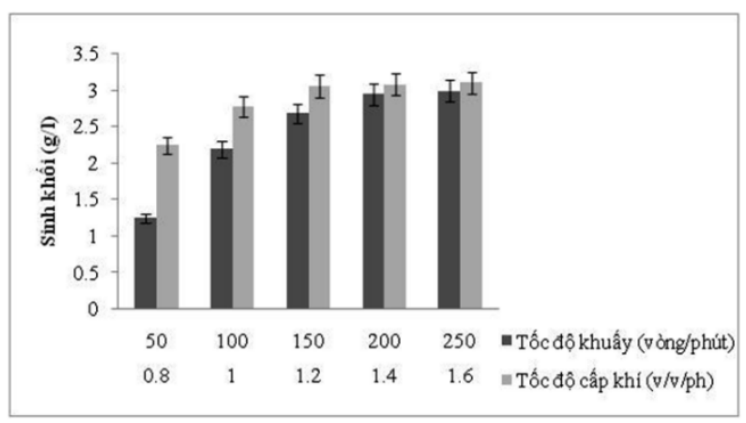

Hình 5. Lựa chọn chế độ khuấy và chế độ thổi khí thích hợp.

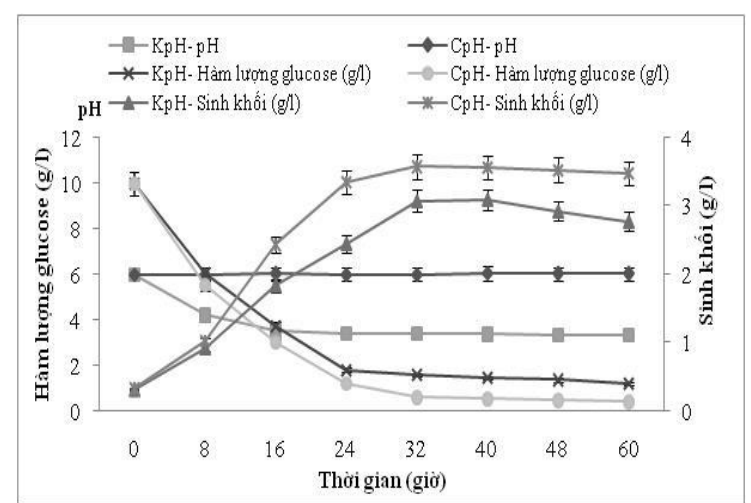

Hình 6. Lựa chọn thời gian nuôi thích hợp trên thiết bị 30 lít.
Nhằm nghiên cứu động học phát triển của tế bào, chủng SB2 được nuôi theo mẻ trên thiết bị 30 lít, tốc độ khuấy 200 vòng/phút; tốc độ sục khí của 1,2 lít khí/lít dịch/phút, dưới điều kiện $\mathrm{pH}$ được kiểm soát và không kiểm soát. Kết quả ở điều kiện nuôi $\mathrm{pH}$ kiểm soát, khối lượng tế bào đạt tối đa $(3,58 \mathrm{~g} / \mathrm{l})$ sau 32 giờ và duy trì trong thời gian còn laii. Tốc độ tiêu thụ glucose cao hơn trong 16 giờ nuôi ban đầu. Vào cuối thời gian nuôi, lượng glucose còn lại là $3,3 \%$. Nuôi ở điều kiện $\mathrm{pH}$ không kiểm soát (pH ban đầu là 6,0 ), sinh trưởng của $S$. boulardii SB2 cũng tăng theo cấp số nhân, sinh khối đạt tối đa là $3,08 \mathrm{~g} / 1$ sau 32 giờ. Giá trị này thấp hơn $14 \%$ so với quá trình nuôi $\mathrm{pH}$ được kiểm soát và cao hơn khi nuôi trên bình lắc. Mặt khác, $\mathrm{pH}$ của môi trường giảm đáng kể đạt giá trị khoảng 3,5 trong 16 giờ đầu tiên do sự hình thành axit. Tốc độ tiêu thụ glucose của chủng SB2 cao hơn trong 16 giờ nuôi ban đầu. Vào cuối thời gian nuôi, lượng glucose còn lại là $12,1 \%$. Theo báo cáo của Muller và cộng sự (2007), độ $\mathrm{pH}$ của môi trường giảm cũng như chức năng hấp thu glucose trong pha sinh trưởng, có thể là do sự tích tụ axit trong môi trường nuôi [16]. Trong nghiên cứu của Chin và cộng sự (2015), khi nuôi chủng Saccharomyces boulardii ATCC-MYA-796 trên thiết bị lên men 16 lít, chứa 8 lít môi trường tối ưu ở chế độ $\mathrm{pH}$ được kiểm soát và không kiểm soát. Khối lượng tế bào tối đa $8,2 \mathrm{~g} / \mathrm{l}$ đạt được sau 16 giờ dưới điều kiện $\mathrm{pH}$ được kiểm soát và 4,0 g/l sau 13 giờ dưới điều kiện pH không kiểm soát [6]. El-Enshasy và cộng sự (2008), nghiên cứu ba kiểu nuôi khác nhau (trong bình lắc và thiết bị lên men 3 lít trong điều kiện $\mathrm{pH}$ được kiểm soát và không kiểm soát) của Saccharomyces boulardii ATCC-MYA-796 trên môi trường CSM bổ sung cao men $(5 \mathrm{~g} / \mathrm{l})$. Trong trường hợp nuôi ở bình lắc, sinh khối đạt tối đa $3,1 \mathrm{~g} / 1$; hàm lượng glucose còn lại $25 \%$. Nuôi trên thiết bị lên men, sinh khối đạt tối đa $4,0 \mathrm{~g} / \mathrm{l}$ và $5,2 \mathrm{~g} / \mathrm{l}$ khi không kiểm soát và có kiểm soát pH sau 12 giờ nuôi. Tỷ lệ tiêu thụ glucose trong trường hợp nuôi cấy trong thiết bị lên men cao hơn so với nuôi cấy bình lắc, còn lại $12 \%$ glucose trong trường hợp $\mathrm{pH}$ không kiểm soát và được tiêu thụ hoàn toàn trong điều kiện $\mathrm{pH}$ được kiểm soát ở mức 5,5 [9]. 


\section{Kết luận}

- Chủng nấm men Saccharomyces boulardii SB2 phân lập từ quả rụng ở Vườn Quốc gia Cúc Phương mang đầy đủ các đặc tính probiotic được lưu giữ tại Bảo tàng Giống Vi sinh vật, Viện Vi sinh vật và Công nghệ Sinh học, Đại học Quốc gia Hà Nội.

- Điều kiện nuôi thích hợp trong bình lắc cho sinh khối cao nhất trên môi trường $\mathrm{YM}$, nhiệt độ $37{ }^{\circ} \mathrm{C}, \mathrm{pH} 6$, tỉ lệ giống cấy $5 \%$, nguồn cacbon là glucose, nguồn nitơ là hỗn hợp của pepton, cao men và cao malt; thời gian nuôi 32 giờ, sinh khối và số lượng tế bào đạt $2,43 \mathrm{~g} / \mathrm{l}$ và $10^{9} \mathrm{CFU} / \mathrm{ml}$.

- Điều kiện nuôi thích hợp trong thiết bị lên men 30 lít của chủng SB2 cho sinh khối cao nhất ở tốc độ khuấy $200 \mathrm{v} / \mathrm{ph}$; tốc độ sục khí 1,2 lít khí/lít dịch/phút; thời gian lên men 32 giờ; sinh khối đạt $3,58 \mathrm{~g} / 1$ dưới điều kiện $\mathrm{pH}$ được kiểm soát và $3,08 \mathrm{~g} / \mathrm{l}$ khi không kiểm soát $\mathrm{pH}$.

\section{Lời cảm ơn}

Các tác giả cảm ơnnhiệm vụ Quỹ gen Khai thác và phát triển nguồn gen vi khuẩn và nấm men nhằm tạo chế phẩm probiotic"và "Bảo tồn và lưu giữ nguồn gen vi sinh vật" đã hỗ trợ kinh phí để thực hiện công trình này.

\section{Tài liệu tham khảo}

[1] FAO/WHO, Guidelines for the Evaluation of Probiotics in Food, Joint FAO/WHO Working Group Report on Drafting Guidelines for the Evaluation of Probiotics in Food London, Ontario, Canada, April 30 and May 1, 2002.

[2] J. Park, M.H. Floch, Prebiotics, probiotics and dietary fiber in gastrointestinal disease, Gastroenterology Clinics of North America 36 (2007) 47-63. https://doi.org/10.1016/j.gtc.2007. 03.001 .

[3] F. Mansour-Ghanaei, N. Dehbashi, K. Yazdanparast, A Shafaghi, Efficacy of Saccharomyces boulardii with antibiotics in acute amoebiasis, World Journal of Gastroenterology 9 (2003)1832-1833. https:// dx.doi.org/10.3748/ wjg.v9.i8.1832.
[4] I. Castagliuolo, M.F. Riegler, L. Valenick, J.T. LaMont, C. Pothoulakis, Saccharomyces boulardii protease inhibits the effects of Clostridium difficile toxins $\mathrm{A}$ and $\mathrm{B}$ in human colonic mucosa, Infection and Immunity 67 1(1999) 302-307.

[5] A. Qamar, S. Aboudola, M. Warny, P. Michetti, C. Pothoulakis, J.T. LaMont, C.P. Kelly, Saccharomyces boulardii stimulates intestinal immunoglobulin A immune response to Clostridium difficile toxin $\mathrm{A}$ in mice, Infection and Immunity 69 (2001) 2762-2765. https:// doi.org/10.1128/IAI.69.4.2762-2765.2001.

[6] T.S. Chin, N.Z. Othman, R.A. Malek, N. Elmarzugi, O.M. Leng, S. Ramli, N.F. Musa, R. Aziz and H. El Enshasy, Bioprocess optimization for biomass production of probiotics yeast Saccharomyces boulardii in semi-industrial scale, Journal of Chemical and Pharmaceutical Research 7, 3(2015)122-132.

[7] D.T.N. Diep, P. George, E. Gorczyca, S. Kasapis, Studies on the viability of Saccharomyces boulardii within microcapsules in relation to the thermomechanical properties of wheyprotein. Food Hydrocolloids 42 (2014) 232-238. https:// doi.org/10.1016/j.foodhyd.2013.07.024.

[8] G.L. Miller, Use of dinitrosalicylic acid reagent for determination of reducing sugar. Analytical Chemistry 31 (1959) 426-428 https://doi.org/ 10.1021/ac60147a030.

[9] H.A. El-Enshasy, A.A. El-Shereef, Optimization of high cell density cultivation of (Probiotic/Biotherapeutic) yeast Saccharomyces boulardii adapted to dryness stress, Deutsche Lebensmittel-Rundschau 104,93 (2008) 89-394.

[10] K. Rajkowska, A.K.-S. Bska, A.Rygala, Probiotic activity of Saccharomyces cerevisiae var. boulardii against human pathogens, Food Technology and Biotechnology 502 (2012) 230236.

[11] R. Zbinden, E.E. Gonczi, M. Altwegg, Inhibition of Saccharomyces boulardii (nom. inval.) on cell invasion of Salmonella typhimurium and Yersinia enterocolitica, Microbial Ecology in Health and Disease, 11 (1999) 158-162. https://doi.org/10. 1080/089106099435736.

[12] D. Czerucka, T. Piche, P. Rampal, Review article: Yeasts as probiotics - Saccharomyces boulardii, Alimentary Pharmacology Therapeutics 26 (2007) 767-778. https://doi.org/10.1111/j.1365 2036.2007.03442.x.

[13] L.V. Mc Farland, P. Bernacoscani, Saccharomyces boulardii. A Review of an Innovative Biotherapeutic Agent, Microbial Ecology in 
Health and Disease 6 (1993)157-171. https://doi. org/10.3109/08910609309141323.

[14] K. Rajkowska, A. Kunicka-Styczynska, Probiotic properties of yeasts isolated from chicken feces and kefirs, Polish Journal of Microbiology 59 (4) (2010) 257-263.

[15] J.L.R. Fietto, R.S. Araujo, F.N. Valadao, Molecular and physiological comparisons between Saccharomy cescerevisiae and Saccharomyces boulardii, Canadian Journal of
Microbiology 50 (2004) 615-621. https://doi. org/10.1139/w04-050.

[16] J.L. Muller, K.L. Protti, M.S. Machado, L.L.V. Lacerda, T.M.B. Bresolin, P.S. Podlech, Comparison of Saccharomyces boulardii growth in an air-lift fermentor and in a shaker, Ciência e Tecnologia de Alimentos 27 (4) (2007) 688-693. http://dx.doi.org/10.1590/S0101-206120070004 00003 . 